\title{
BARROCO: A TEMPESTADE NA BIBLIOTECA
}

OU

\section{O GRANDE TEATRO DA FUNDAÇÃO}

\author{
Diego Cervelin ${ }^{1}$
}

Desde que Heinrich Wölfflin, nos últimos vinte anos do século XIX, se interessou por trazer à tona as formas arquitetônicas do século XVII conferindoIhes caráter autônomo de estilo histórico determinável, não é nenhuma novidade que os estudos sobre o barroco pudessem polarizar - quase sempre em um tom colérico - os pesquisadores da arte e da cultura. Em terras do Brasil, não chega a ser de todo descabido recordar a severíssima crítica operada por Sérgio Buarque de Holanda em Raízes do Brasil. O livro, que pretende detectar a avalanche de equívocos que teria povoado o passado nacional com as vistas voltadas para a concretização de um projeto de emancipação e progresso na linha da história brasileira, apresenta em seu quarto capítulo uma impugnação explícita ao passado colonial. E isso na medida em que Holanda utiliza em tom diferido a batalha agônica entre ladrilhadores e semeadores a que se referia Padre Antônio Vieira no Sermão da Sexagésima².

A questão que ocupa o fundo deste cenário crítico mais específico não ultrapassa, entretanto, o pensamento de um ponto de apoio ou de um porto

\footnotetext{
${ }^{1}$ Graduado em Direito pela Universidade Federal de Santa Catarina. Este ensaio surgiu como decorrência do projeto de iniciação científica $\mathrm{PIBIC/CNPq}$ intitulado $A$ pervivência do barroco na cultura brasileira - leituras da revista Barroco entre 1969 e 1978, desenvolvido durante o biênio de 2006 e 2007, no Núcleo de Estudos Literários e Culturais (NELIC/CCE/UFSC), sob a orientação da Profa. Dr ${ }^{\mathrm{a}}$. Susana Célia Leandro Scramim.

2 Enquanto Vieira se esmerava em apresentar a supremacia do poder salvador dos semeadores da palavra de Deus e impugnava o discurso daqueles que, preocupando-se meramente com a beleza das sentenças utilizadas, agiam conforme ladrilhadores, Sérgio Buarque de Holanda invertia de forma inexorável a fórmula valorativa. Identificava, então, o semeador ao passado agrário do Brasil e à falta de projeto definido para a ocupação das terras da colônia por parte dos portugueses. Os ladrilhadores, por outro lado, segundo o autor de Raízes do Brasil, estariam mais próximos dos espanhóis e, longe de figurarem como estetas inconse-qüentes, teriam demonstrado maior acuidade técnica em sua atividade colonizadora. Não causa nenhum estupor que Sérgio Buarque de Holanda se refira diretamente aos planos urbanísticos geométricos daquelas cidades criadas na América espanhola. A impugnação do status quo colonial não se traduzia, porém, como completo desapreço pelo barroco. Muito pelo contrário, como se pode depreender da admiração que Sérgio Buarque de Holanda exala em "Notas sobre o barroco", publicado no livro Tentativas de Mitologia, da década de 50.
} 
seguro como sendo a mais pura demonstração de uma necessidade na ordem do dia. Tratava-se, nesse sentido, de tentar produzir a materialidade de que dependia a metafísica da identidade e não menos de pensar a comunidade da Nação como corpo um formado por muitas cabeças - omnes et singulatim como Michel Foucault formularia em seu curso no Collège de France durante 1977 e 1978. Ou ainda, em outros termos: refletindo sobre o passado colonial e procurando seus possíveis equívocos, tratar-se-ia de traçar as linhas e os limites do programa a ser adotado para a constituição do Uno enquanto Nação, aquele bloco destinado percorrer os trilhos do desenvolvimento. O passado colonial, então compreendido como signo da servidão e do atraso, deveria ceder seu espaço na cena interpretativa nacional para outro momento capaz de ser apreendido como demonstração das bases fundadoras da autonomia brasílica.

No campo mais específico da construção historiográfica da literatura da Terra dos Papagaios, o trabalho de Antônio Cândido em sua Formação da Literatura Brasileira também não deixou de desempenhar um corte cirúrgico em relação ao barroco. Isto é: foi extirpado como aquele corpo expúreo que só poderia atrapalhar o funcionamento da máquina identitária. Eis que o trabalho literário dos séculos XVII e XVIII, podia pensar Cândido no afã de rostificar os contornos dos processos formadores da Nação, não foi pródigo em estabelecer uma efetiva relação entre escritores, obras e leitores, não demonstrou a capacidade de estabelecer qualquer sistema e, sob uma maquiagem tropicalizada, tão somente reproduziu as formas metropolitanas em vez de servir para construir algo efetivamente autóctone. Esses argumentos, como já não é novidade, deveriam enfurecer um entusiasta colérico como Haroldo de Campos, que, desde os textos recolhidos em $A$ arte no horizonte do provável, procurava resgatar o potencial de novidade existente na linguagem barroca especialmente através de sua proposta de leitura sincrônica. Difícil seria negar, por outro lado, que os resultados de sua ira hercúlea haveriam de tomar uma forma mais contundente, por exemplo, no ensaio apresentado em Portugal a 
respeito da razão antropofágica ${ }^{3}$ e no libelo acusatório contra o seqüestro de Gregório de Matos promovido por Cândido nos anos $50^{4}$.

Para além disso, em 1969, no mesmo ano em que Haroldo de Campos lançou a coletânea de seus textos sobre a sincronia e as tentativas de resgate das vozes esquecidas de Sousândrade, Kilkerry e Gregório de Matos, em Minas Gerais, uma revista tomava para si a responsabilidade de estudar as formas do barroco no Brasil e nos demais países latino-americanos. Trata-se não menos de Barroco, que continua a ser publicada ainda hoje, originalmente idealizada e dirigida pelo poeta e ensaísta mineiro Affonso Ávila, logo após ter assumido a direção do Centro de Estudos Mineiros, órgão vinculado à Universidade Federal de Minas Gerais ${ }^{5}$.

O projeto inicial da revista Barroco previa uma divisão em três seções básicas destinadas a albergar estudos sobre o fenômeno barroco, ou seja, aquela dedicada a ensaios crítico-teóricos, outra para resenhas e notas, além de uma seção para registros de eventos considerados relevantes. Além da constante presença de Affonso Ávila, entre os estudiosos que contribuíram com ensaios durante os primeiros nove anos de publicação, figuraram os nomes de Myriam Ribeiro de Oliveira, Francisco Iglesias, German Bazin, Francisco Curt Lange, Benedito Nunes, Cesáreo Bandera, Cristina Ávila, Adalgisa Arantes do Nascimento, Silviano Santiago, Hélio Gravatá, Sylvio de Vasconcellos e Aracy Amaral. Os artigos publicados perpassavam de forma predominante o estudo da história da arte pictórica mineira, da arquitetura, da música e também da literatura. O espaço aberto à apresentação de resenhas primava tanto pela observação de livros e monografias sobre o desenrolar histórico do barroco

\footnotetext{
${ }^{3}$ Publicado originalmente na Revista Colóquio/Letras, Lisboa, Fundação Calouste Gulbekian, n 62, julho de 1981, sob o título "Da razão antropofágica: a Europa sob o signo da devoração". O ensaio também foi publicado em revistas no México, Argentina, Estados Unidos e na França. No Brasil, o texto foi republicado sob a variação "Da razão antropofágica: diálogo e diferença na cultura brasileira" no Boletim Bibliográfico da Biblioteca Mário de Andrade, São Paulo, v. 44, no 1-4, jan.-dez. 1983 e no livro Metalinguagem \& outras metas: ensaios de teoria e crítica literária. 4 ed. São Paulo: Perspectiva, 2004, p. 231-255.

4 O seqüestro do barroco na formação da literatura brasileira: o caso Gregório de Matos, publicado em 1989, pela Fundação Casa Jorge Amado, na cidade de Salvador.

${ }^{5}$ Affonso Ávila esteve à frente do projeto editorial de Barroco entre os anos de 1969 e 1996, quando cedeu espaço para que sua filha, a historiadora e professora da UFMG, Cristina Ávila, desse seguimento ao projeto. Nos primeiros dez números da revista a periodicidade de publicação era anual. Em fins da década de 70 passou a ser bianual e, já nos anos 90 , dependendo de verbas estatais, perdeu a regularidade. Inicialmente, Barroco estava vinculada ao Centro de Estudos Mineiros e hoje segue como um dos projetos do Centro de Pesquisas do Barroco Mineiro, também da UFMG.
} 
quanto pela análise de projetos de lei destinados à conservação do patrimônio histórico e artístico brasileiro. Mas também vale lembrar que nesta mesma seção entravam as análises de guias turísticos das cidades históricas ${ }^{6}$ de Minas, bem como de programas de seminários.

Longe de servir como veículo para um engajamento de ruptura com o programa identitário adotado pelo governo da ditadura militar, um elemento marcante e capaz de evidenciar a particularidade do periódico idealizado por Ávila está na percepção do barroco como um evento que possui marcas específicas em seu desenrolar no espaço da América Latina. Tendo isso em mente, é possível pensar que Barroco talvez tenha sido até hoje a única revista que tenha conferido uma tamanha importância - visceral - a essas questões. Exemplarmente, seria uma pena deixar de mencionar que, no primeiro número publicado no ano de 1969, a apresentação assinada pelo editor pretendia filiar a linha teórica da revista à compreensão sincrônica dos eventos históricos. Afirmava-se, pois, a existência de afinidades e similitudes que aproximavam o século XVII ao século XX. Isso tanto no âmbito da estética literária e da política como também naquele referente às experiências existenciais dos homens da segunda metade do século $X X^{7}$. A revista, diante disso, procurava se apresentar como um meio de levantar questões que tratassem dos estudos do barroco em sintonia com a atualidade crítica dos anos 60 - sob o manto de Roman Jakobson ${ }^{8}$, mais precisamente. Mas, além disso, por se presumir um veículo privilegiado para a comunicação dos estudos desenvolvidos naquele momento, a revista não deixou inclusive de se pautar por uma certa institucionalização de uma comunidade de literatos e eruditos. Isto porque a mola propulsora dos debates ali apresentados partia da compreensão de um comum que localizava no fenômeno barroco - e de modo especialíssimo naquele que teve lugar em Minas Gerais - o centro, melhor dizendo, a raiz do

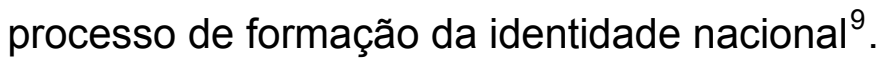

\footnotetext{
${ }^{6}$ Veja-se, por exemplo, a seção de resenhas do quarto número da revista.

7 ÁVILA, Affonso. "Apresentação". In: Barroco, n. 1, Belo Horizonte, 1969, p. 07.

${ }^{8}$ No segundo número de Barroco, publicado em 1970, na seção destinada às notas, há a transcrição de um trecho de uma entrevista concedida por Jakobson a Laís Correa de Araújo. O texto foi originalmente publicado no Suplemento Literário do "Minas Gerais" de 09 de novembro de 1968, por ocasião da visita do lingüista às cidades mineiras.

${ }^{9} \mathrm{Em}$ tom retrospectivo, Affonso Ávila se refere às Minas Gerais de um modo muito especial no texto "O salto atlântico do barroco" publicado originalmente como introdução ao catálogo da
} 
Nesse sentido, a proposta de ler o barroco a partir da sincronia tal qual defendida por Ávila no primeiro número da revista até podia encontrar no trabalho do Haroldo de Campos um certo regime de consonâncias ${ }^{10}$. Porém, muito embora Affonso Ávila procurasse atrelar os estudos da Barroco à utilização do corte do instante sobre a linha do tempo na esteira de uma pragmática do escolher a fim de atualizar a prática criativa, não era exatamente isso o que se podia observar entre as páginas da revista. Poucos foram os ensaios destinados a evidenciar as relações entre o presente e o passado do Brasil colonial, que em sua na maior parte restrito ao espaço das Minas Gerais. Eis que aquilo que se nos apresenta é um grandioso conglomerado de observações diacrônicas, destinadas a descrever os séculos XVII e XVIII em Minas como o período de gestação do Brasil.

Assim nem chega a causar estranhamento que o principal ponto de

exposição "Brazil Body \& Soul", realizada no Guggenheim Museum de Nova lorque em 2001, e, posteriormente, reunido ao livro Circularidade da elipse: "O barroco [...] encarnava, vivenciava e exprimia, por seus canais ideológico-culturais, a dualidade de inquietude e também de esperança que no fundo casava a espiritualidade devocional (O Paraíso) e a irreprimível terrenalização dos sentidos (o conúbio interdito Adão / Eva) do homem sitiado e conturbado assim por paradoxos e paroxismos. Tendo em foco central o quadro brasileiro dos Seiscentos / Setecentos, diremos que, a partir do sentimento que impulsionara, ainda nos Quinhentos do Descobrimento, o 'pedreiro anônimo de Itamaracá / plantando a igreja inaugural na ilha' - para valer-nos dos versos do poeta, conventos, mosteiros, colégios, igrejas e capelas de portos e periferias agrárias, com funções internas de pedagogia teológica, ascese e meditação e missões internas de liturgia, pregação e catequese, formam como que, na faixa litorânea e adjacências, a disseminação de uma espécie de barroco de cabotagem, de norte a sul do paíscolônia, barroco que não deixaria de esparzir tanto a fé quanto o saber, tanto a norma ética quanto o lazer. Simultaneamente a essa primeira modalidade inseminadora litorânea de cultura ao nível explícito já do barroco, outra e segunda modalidade se expandiria, em feição porém mais primária e exparsa, no rumo de sertões e fronteiras, adicionando à construção de fortes e aos marcos de conquistas a ação missionária e a edificação de templos rurais e rústicos, tudo porém num mimetismo que não se arrefecia ao estoicismo denodo andarilho de padres e frades, muitos deles mestres de aula e artífices improvisados, à frente a determinação da milícia jesuítica e o desprendimento material dos franciscanos. A terceira modalidade remarcadora da fé ainda em marcha residual barroca iremos surpreender, em patamar mais elevado e coeso de cultura [grifo nosso], no território insulado entre montanhas das Minas Gerais do ouro e do diamante, já no caso - vigente o Setecentos - em desenho e desejo de fixação urbana e social, território fechado à tutela das ordens confessionais regulares, embora num mesmo pacto de poder político e poder religioso". ÁVILA, Affonso. "O salto atlântico do barroco". In:__. Circularidade da ilusão e outros textos. São Paulo: Perspectiva, 2004, pp. 1516.

${ }^{10}$ Relações entre Haroldo de Campos e Affonso Ávila podem ser reconhecidas, por exemplo, desde a década de 50 , quando o poeta paulista participou do último número da revista Tendência, dirigida por Ávila. Em 1962, o poeta mineiro também publicou um fragmento de "Carta sobre a usura" e um estudo intitulado "Carta do solo - poesia referencial" no segundo número de Invenção - revista de arte de vanguarda. Dois anos depois, Ávila também chegou a publicar na mesma revista da vanguarda concretista o poema "orografia". Lembre-se ainda que, em 1963, com a colaboração de Affonso Romano de Sant'Anna, Affonso Ávila organizou a Semana Nacional de Poesia de Vanguarda no hall da reitoria da Universidade Federal de Minas Gerais, evento do qual participaram os irmãos Campos e Décio Pignatari. 
partida para a leitura do barroco nos textos presentes na revista seja o historicismo de Heinrich Wölfflin. Tratava-se, então, de pesquisar sobre os métodos utilizados na construção das capelas mineiras, sobre 0 desenvolvimento da escultura, sobre as técnicas e materiais utilizados na pintura, sobre como determinar as fases evolutivas do estilo barroco da arte in loco. Ou então, buscava-se resgatar das bibliotecas esquecidas das pequeninas cidades de Minas os documentos - incluindo aí recibos ou atas de reuniões - relativos à vida de Aleijadinho, à atividade mineradora. Ainda havia um grande número de trabalhos voltados para o levantamento bibliográfico de obras raras que versassem tanto sobre Minas Gerais quanto sobre biografias de ilustres dos séculos XVII e XVII e Hélio Gravatá ocupava o lugar de expert para esses assuntos. Daí que se possa dizer que a necessidade de encontrar um documento era determinante. No entanto, isso de modo algum significava que esses textos resgatados pudessem ser lido como um arrazoado de potências reverberantes no presente. Eles serviam antes para a admiração, culta e cultuosa dos olhos: era preciso saber a procedência do documento, suas características físicas, o assunto ao qual estava ligado, seu autor. Essa mesma relação não deixava de se ter com a produção literária. $E$, nesse sentido, observe-se o apego, que diria familiar, demonstrado por Ávila ao tratar de obras publicadas nos Setecentos de Minas como Triunfo Eucarístico e Áureo Trono Episcopal.

Eis que o aporte quase nunca escapava da necessidade de encontrar um documento perdido, isto é, de encontrar a verdadeira certidão de nascimento do Brasil. Tendo o documento em mãos, desencravado do meio das prateleiras poeirentas ou dos escombros das capelas esquecidas, ele estava destinado a conhecer uma nova vida - como patrimônio a ser conservado na assepsia secularizada do museu. O barroco era aquilo que deveria ser resgatado a qualquer custo ${ }^{11}$. E isso não somente porque talvez lá no fundo - pudesse fornecer uma centelha de criatividade ao artista fatigado

\footnotetext{
${ }^{11}$ Acrescente-se a observação feita por Ávila no texto "Brasil: do barroco ao neobarroco. Três reflexões", também incluído em Circularidade da elipse: "[...] é no barroco que iremos encontrar sem dúvida o único suporte realmente válido para a fixação de uma linha de tradição ao longo da história da criação artística no Brasil". ÁVILA, Affonso. "Brasil: do barroco ao neobarroco. Três reflexões". In: Circularidade da ilusão e outros textos. São Paulo: Perspectiva, 2004, p. 40.
} 
do século XX. O estudo dos séculos XVII e XVIII queria antever a formação de uma nacionalidade pautada pela miscigenação carnavalizada de indígenas, europeus e de africanos. Queria dizer, em última análise, que o Brasil do século XX era o resultado de uma mistura feliz moldada em tons lúdicos.

Isso chamava ainda mais a atenção no texto $O$ elemento lúdico nas formas da expressão do barroco, publicado no segundo número da revista e cujas centelhas podem ser encontradas em outros textos reunidos em O lúdico e as projeções do mundo barroco. Ali Ávila trata de lembrar que o homem europeu do século XVII vivia sob o constrangimento dos tenebrosos embates decorrentes da Reforma e da Contra-Reforma. Era um homem atordoado, mas, ao mesmo tempo, sensível ao apelo do visual e às palavras persuasivas ${ }^{12}$. Daí que a arte barroca, surgindo como válvula de escape desse cenário belicoso, não seria apenas estilo artístico; tal qual apresentado na revista, ele seria antes a expressão de um verdadeiro estilo de vida ${ }^{13}$. Isto porque, vindo para as terras do Novo Mundo, o homem europeu teria tido a oportunidade de entrar em contato com um espaço idílico - em apresentação à beira do mais arraigado ufanismo quase naïf - capaz de curar a dores da desagregação religiosa. Se se podia falar que o ser europeu estava em crise, era através do contato com o exotismo da outra terra, na esfera da arte, que ele podia colocar-se como senhor da criação, como veículo da expressão da mutabilidade, das transgressões lúdicas. Não é por acaso que Ávila, partindo dos estudos feitos por Huizinga em Homo ludens, pudesse falar então de um pacto lúdico:

\footnotetext{
${ }^{12}$ Dizia Ávila: "O artista barroco foi [...] histórica e existencialmente, um ser em crise, sua arte registrou, como um grande radar, as oscilações das idéias e as linhas cruzadas das formas de expressão em mudança. E esse painel vibrátil e sensível ao captar e percutir uma temporalidade agudamente dilemática, não o fez já ao nível de diafaneidade do Quinhentos. A realidade em que se inseria ditava condições diferentes, passava a confinar a inteligência a uma faixa de subjetividade que não compreendia mais a alternativa crítica do racionalismo, a perspectiva antropocêntrica do humanismo. A linguagem antes de âmbito denotativo da renascença reflui então às simbologias de fundo religioso e mitológico, recobrindo de metáforas e claro-escuros o mundo em representação. As manchas pictóricas e o dinamismo escultório, tanto quanto a reverberação sinestésica da imagem literária, envolvem de uma nova fantasia formal o núcleo da mensagem ou do pretexto barrocos, refugindo com isso o criador ao compromisso declarado de objetividade com o real. $O$ artista do Seiscentos e seus desdobramentos sente, de modo mais intenso que o renascentista, a paixão da aventura humana, porém é compelido a contê-la, a disfarçá-la, a dissimular os seus apelos e as suas vertigens, sublimando-os através de uma criação em cujo processo o jogo das formas desempenha função preponderan-te". ÁVILA, Affonso. "O elemento lúdico nas formas da expressão do barroco". In: Barroco, n. 2, Belo Horizonte, 1970, p. 14.
}

${ }^{13}$ ÁVILA, Affonso. Op. cit., p. 09. 


\begin{abstract}
Este [o homo ludens] se definirá pela capacidade de jogar, imanente tanto na ação de ordenar, segundo um desempenho livre da consciência e da imaginação, a objetividade do universo concreto, quanto de articular como objetos novos a correalidade das formas da criação subjetiva. Muitas dessas formas passaram a inserir-se no sistema de relações sancionado pelas sociedades humanas, assumindo aqui feições e convencionando regras próprias, isso acrescentamos - mediante o que poderíamos chamar um pacto lúdico, ou seja, a confluência natural e tácita, no ser social, dos impulsos individuais para o jogo [...] O pacto lúdico, na sua natureza de epifenômeno de abrangência social, isto é, de cláusula estipulada e aceita das relações entre os homens, poderá explicar, assim, muito daquele mundo de invenção e fantasia criadora, daquele estilo de vida peculiarís-simo de vida que foi o barroco ${ }^{14}$.
\end{abstract}

Leia-se, no entanto: o homem, valendo da arte como válvula de escape, para constituir-se como ser social, precisa tentar dispor sobre o espaço da ruína. Mas é bom lembrar que a proposta de Ávila já não tem mais como destinatário privilegiado o homem nascido na Europa. Trata-se, antes disso, de querer dizer aos brasileiros que eles são o fruto de um bom encontro verdadeira manifestação gloriosa e triunfalista. O barroco, podia sustentar Ávila, deveria ser apreendido como o evento que determina a maneira de sentir, de ver e de expressar própria das terras do Brasil ${ }^{15}$. E então, se Haroldo de Campos dizia sincronicamente que a literatura brasileira teria surgido com o domínio do rebuscado código lingüístico de um Gregório de Matos, para o grupo da revista Barroco - especialmente Affonso Ávila - o Brasil teria sido criado e arquitetado já no áureo tempo de Minas pelas mãos de Aleijadinho.

Por outro lado, a retomada deste escultor-arquiteto de aspecto deformado e muitas vezes destinatário das mais profundas demonstrações de piedade cristã já não era nenhuma novidade para os ilustres signatários da revista. De modo especial, Affonso Ávila tinha consciência disso e oportunamente fazia referência à leitura feita por Mário de Andrade, em 1928, no texto O Aleijadinho, que veio a fazer parte de Aspectos das Artes Plásticas no Brasil. Ali pode perceber-se a tentativa de reconhecer a existência de uma conexão entre o aspecto físico do escultor - mulato, deformado, marginal - e o relaxamento como centro deslocado da legalidade que a metrópole relegou à

\footnotetext{
${ }^{14}$ ÁVILA, Affonso. "O elemento lúdico nas formas da expressão do barroco". In: Barroco, n. 2, Belo Horizonte, 1970, pp. 10-11.

${ }^{15}$ ÁVILA, Affonso. "Pequena Iniciação ao Barroco Mineiro". In: Barroco, n. 7, Belo Horizonte, 1975 , p. 12. O mesmo argumento foi utilizado pelo autor, por exemplo, na página 40 do texto "Brasil: do barroco ao neobarroco. Três reflexões", já citado anteriormente.
} 
colônia. Parecia, portanto, que uma brasilidade não poderia ser definida senão através da mestiçagem que funde elementos díspares e da transgressão de uma ordem estrangeira. Nesse sentido, Ávila podia muito bem procurar confirmar aquilo que Mário de Andrade dizia a respeito de Aleijadinho:

\begin{abstract}
Era de todos, o único que se poderá dizer nacional, pela originalidade das suas soluções. Era já um produto da terra, e do homem vivendo nela, e era um inconsciente de outras existências melhores de alémmar: um aclimado, na extensão psicológica do termo. Mas, engenho já nacional, era o maior boato-falso da nacionalidade, ao mesmo tempo que caracterizava toda a falsificação da nossa identidade civilizada, feita não de desenvolvimento interno, natural, que vai do centro pra periferia e se torna excêntrica por expansão, mas de importações acomodatícias e irregulares, artificial, vianda do exterior [...] É a solução brasileira da Colônia. É o mestiço e é logicamente a independência. Deforma a coisa lusa, mas não é uma coisa fixa ainda [...] É um verdadeiro aborto luminoso, como abortos luminosos foram a valorização da borracha e do café e por muitas partes a industrialização de São Paulo ${ }^{16}$.
\end{abstract}

Diante disso, vale observar que, para Ávila, ao tomar como norma a argumentação taumatúrgica do arconte modernista que remetia a origem do nacional a Aleijadinho, a identidade não era mais um problema. Tratava-se antes de já poder cultuá-la, nem que para isso fosse necessário levantar a mais tremulante das bandeiras a fim de procurar desentranhar das cinzas e escombros do passado e retirar da poeira as provas da mistura feliz que caracterizaria a identidade brasileira. Eis, então, que em um ensaio intitulado Pequena iniciação ao barroco mineiro, publicado no sétimo número de Barroco, Affonso Ávila, reafirmando sua compreensão do barroco como "idéia definidora daquilo que exprime e dá sentido [...] a uma atitude filosófica, estética e existencial [...] do homem latino-americano"17, nos diz que, no Brasil, materializando o sistema propugnado pelo pacto lúdico, Aleijadinho seria o máximo representante de uma linguagem autônoma e amadurecida da fantasia nacional pela assimilação e reavaliação de heranças formais européias no território das Minas. E, por sua vez, a arquitetura desenvolvida durante o ciclo aurífero, inicialmente caracterizada por fachadas modestas e em contraste com interiores ricamente ornamentados, teria encontrado sua plenitude de feição

${ }^{16}$ ANDRADE, Mário de. "O Aleijadinho". In: Aspectos das artes plásticas no Brasil. Belo Horizonte: Itatiaia, 1984, p. 41.

${ }_{17}$ ÁVILA, Affonso. "Pequena Iniciação ao Barroco Mineiro". In: Barroco, n. 7, Belo Horizonte, 1975, p. 07. 
nacional na Igreja de São Francisco de Assis, cujo projeto é de Aleijadinho. Mas o autor ainda iria mais além ao definir Ouro Preto como uma espécie de cidade-síntese ou de cidade-documento da formação brasileira ${ }^{18}$.

Nesse sentido, não é de estranhar que, no mesmo sétimo número da revista e localizado logo a seguir ao ensaio de Ávila, Aracy Amaral pudesse publicar A Hispanidade em São Paulo. Da Casa Rural à Capela de Santo Antônio. Tratava-se não menos de um trabalho destinado a investigar a arquitetura do interior paulista durante os primeiros anos da presença européia no Brasil a fim de comprovar uma série de intercâmbios de informação entre as terras colonizadas do Novo Mundo e as decorrentes possibilidades de percepção de uma matriz identitária. Mas observe-se, por outro lado, que este estudo também se apresentava, muito oportunamente, como um seguimento às análises feitas por Mário ainda durante a década de 20. Em outros termos: é possível dizer que Aracy Amaral procurava, através da análise das formas arquitetônicas, evidenciar a manifestação de uma raça, e o termo utilizado é este mesmo, que jogava com as formas vindas de fora ${ }^{19}$.

Para além, no meio de toda essa parafernália barroquizada com tanto voluntarismo, o apreço pelas descrições arquitetônicas não deixou de ser recorrente. Depois de bem definidas as características do ser nacional como produto de uma fusão lúdica e que ainda deveria receber a qualificação de "feliz", as construções só poderiam manifestar um caráter testemunhal - como documento de Verdade - e conferir um aspecto de solidez à tal noção de identidade. Entretanto, o interesse não se volta para qualquer prédio. Fala-se muito dos palácios dos ex-governadores, das câmaras municipais, das casas senhoriais, das igrejas, das capelas - todos muito bem catalogados até a exaustão. Serviriam, pois, estas construções de reflexo imediato da identidade, como a face permanente da Nação - os seus monumentos. Daí que, logo em seguida, se pudesse começar a exigir e falar de uma série de leis referentes à

\footnotetext{
18 Lembre-se, todavia, que Affonso Ávila escrevia sobre esta idéia de síntese, de matriz notadamente hegeliana, localizando-a temporalmente em um período muito anterior àquele percebido por Antônio Cândido - o supra-regionalismo de Guimarães Rosa - em seu ensaio sobre a compreensão de literatura e subdesenvolvimento, escrito para fazer parte da coletânea intitulada América Latina e su literatura, organizada por Cézar Fernández Moreno a cargo da UNESCO, em 1972. Este ensaio foi reunido posterior-mente ao livro $A$ educação pela noite $e$ outros ensaios.

${ }_{19}$ AMARAL, Aracy A. "A Hispanidade em São Paulo. Da Casa Rural à Capela de Santo Antônio". In: Barroco, n. 7, Belo Horizonte, 1975, pp. 21-70.
} 
salvaguarda do patrimônio arquitetônico colonial e à atuação do órgão estatal competente, o IPHAN. E, note-se que não era nenhuma raridade encontrar entre as últimas páginas de cada volume da revista algumas tantas menções a essas leis. Ainda no sétimo número, por exemplo, numa clara tentativa de evitar a dispersão, o encarregado-mor dos levantamentos e compilações, Hélio Gravatá, apresentava um longo arrazoado das leis sobre o assunto desde $1925^{20}$.

Justamente em função disso, a relação de identidade e monumentalização ${ }^{21}$ tal qual defendida não deixa de ser problemática. Lembrese não menos da situação em que o Brasil se encontrava quando Barroco começou a ser publicada. Já não era mais uma "republiqueta das bananas", mas era o país do futuro que a ditadura a ferro e fogo tanto se empenhava em produzir: "Brasil. Ame-o, ou deixe-o". Assim, entre os textos publicados na revista Barroco já não se tratava mais de reconhecer a cultura brasileira sob o signo da falta, do subdesenvolvimento - temas caros a Antônio Cândido. E aparentemente nada poderia lembrar a nostalgia de uma Europa distante. Isto porque acontece justamente o contrário: há o grande ato calibanesco da autonomia do homem do Novo Mundo. Ou seja, o exótico Calibán da peça shakespeariana não queria mais estar à sombra do europeu, Próspero. Este Calibán, que só pôde ser chamado como tal depois de ter recebido as lições de seu amo e ter sido nomeado como tal, quer a liberdade. No entanto, é bom observar que, muito embora se diga autônomo, Calibán sempre está em dívida com Próspero: porque este existiu também pôde existir um Calibán. Pode-se dizer, então, que a lógica da identidade tal qual determinada pela revista se

\footnotetext{
${ }^{20}$ GRAVATÁ, Hélio. "Patrimônio Histórico e Artístico de Minas Gerais. Conservação e Proteção Oficial". In: Barroco, n. 7, Belo Horizonte, 1975, pp. 102-121.

${ }^{21} \mathrm{Em}$ seu verbete sobre a arquitetura, publicado no número de maio de 1929 da revista Documents, Georges Bataille falava justamente sobre o potencial fisionômico das grandes construções que dominaram por séculos as cidades européias: os palácios, as catedrais, os castelos. Foi também contra estas construções que se teriam voltado os revoltosos na queda dos Bourbon franceses: "a arquitetura é a expressão do próprio ser das sociedades, da mesma maneira que a fisionomia humana é a expressão do ser dos indivíduos. Entretanto, é sobretudo a fisionomias de personagens oficiais (prelados, magistrados, almirantes) que essa comparação deve ser relacionada. Com efeito, apenas o ser ideal da sociedade, aquele que ordena e proíbe com autoridade, se exprime nas composições arquiteturais propriamente ditas. Assim, os grandes monumentos se elevam como diques, opondo a lógica da majestade e da autoridade a todos os elementos perturbadores: é sob a forma das catedrais e dos palácios que a Igreja ou o Estado se dirigem e impõem silêncio às multidões". BATAILLE, Georges. "Arquitetura" (tradução de Marcelo Jacques de Moraes e João Camillo Penna). In: Revista Inimigo Rumor, n. 19, $2^{\circ}$ semestre de 2006 e $1^{\circ}$ semestre de 2007, p. 79.
} 
determina enquanto oikonimia de uma dualidade: está sempre diante da necessidade de rearticular constantemente categorias separadas, que se opõem e, ao mesmo tempo, se relacionam visceralmente. Dessa forma, se o europeu poderia reconhecer-se como detentor de uma propriedade, de uma pureza, o homem exótico do Novo Mundo, dentro dos meandros de significação e subjetivação daquela máquina abstrata de rostidade que Deleuze e Guattari estudaram nos Mil Platôs, precisaria se dizer detentor de uma impropriedade - fruto da fusão de três entes, da excentricidade, da marginalidade: era isso que o identificava.

Por trás da máquina abstrata que confere a identidade existe o artifício decisório do limite, sobre o estabelecimento do limite, ou, como diria o jurista alemão Carl Schmitt, sobre a decisão a respeito do caso-limite. Isso quer dizer que a determinação do sentido de qualquer coisa - a sua propriedade ou impropriedade - depende de uma decisão fundadora e soberana capaz de criar as linhas que possam diferenciar e separar em formas unitárias o "eu do "outro". Resumindo, seria bem possível que a fórmula assumisse o seguinte aspecto: a decisão se apresenta enquanto separação fundamental para o arranjo de uma condição de normalidade, ou seja, é de-cisão. E não teria sido senão este o estratagema utilizado por Schmitt ao estudar, com base especialmente em Thomas Hobbes e sua noção de que Autoritas, non veritas facit legem, os fundamentos da soberania e do decisionismo para a constituição da unidade do Estado através da decretação do estado de exceção. Ao determinar estes limites inexoráveis a fim de regular a existência que habita a superfície da terra, o homem só pode pretender apresentar-se como sendo deus. Ele desdobra o fiat divino no momento da gênese e ocupa o trono glorioso outrora ocupado exemplarmente pelo Autor do auto sacramental El gran teatro del mundo, escrito por Calderón de la Barca: "De mi voz un suspiro, de mi mano un rasgo es quien te informa a su oscura materia le da forma" 22 .

Giorgio Agamben, em seu elogio à profanação, diz que sacro se define como uma esfera de separação que interdita ao uso dos homens certas coisas

\footnotetext{
${ }^{22}$ BARCA, Pedro Calderón de la. "El gran teatro del mundo". In:_. Teatro del Siglo de Oro (a cura di Mario Socrati, Maria Garzanti, Carmelo Samonà). Milano: Garzanti, 1990, pp. 864.
} 
e certas situações ${ }^{23}$. Assim, se outrora se podia reclamar que o estar à sombra do cânone europeu, com todo o seu peso de sacralidade, relegava o barroco à exclusão, ao procurar resgatá-lo como identidade, a relação de poder subjacente continua sendo intimamente relacionada àquela que se critica. $A$ de-cisão sobre essa identidade outra - a mestiçagem na forma de fusão feliz que se pretende rostificar através de Aleijadinho - desdobra, secularmente, o mesmo mecanismo de separação, uma vez que continua a existir aquela figura de proa tão cara à metafísica ocidental capaz de determinar uma essência, um sujeito $^{24}$. Nesse sentido, o que diriam as páginas da revista Barroco é um constante "é necessário separar". Trata-se, pois, de uma formulação que toma forma de maneira explícita pelo modo em que os artigos reiteram incessantemente a exigência de defesa do patrimônio arquitetônico através da instituição e como sendo tal, através da atuação do Estado, mas muito mais quando se procura levar os documentos recolhidos às salas do museu como sendo provas da unidade e da materialidade identitária de contornos cultuosos.

Vale observar que a de-cisão, sempre uma decisão excepcional e que conjuga tanto autoridade quanto poder, no entanto, para os corpos que existem e que sustentam a vida, não passa de um artifício que procura escamotear um indecidível - e note-se que Schmitt era muito enfático ao afirmar que toda normalidade antes necessitava de que se criasse uma situação ${ }^{25}$. Diante disso, Agamben pode sustentar que aquilo que deve ser excluído não se desliga pura e simplesmente da norma, mas mantém uma relação com ela por meio de sua suspensão:

A exceção é uma espécie de exclusão. Ela é um caso singular, que é
excluído da norma geral. Mas o que caracteriza propriamente a
exceção é que aquilo que é excluído não está, por causa disto,
absolutamente fora de relação com a norma; ao contrário, esta se
mantém em relação com aquela na forma da suspensão. A norma se
aplica à exceção desaplicando-se, retirando-se desta. O estado de

23 "Sacre o religiose erano le cose che appartenevano in qualche modo agli dèi. Come tali, esse erano sottrate al libero uso e al commercio degli uomini, non potevano essere vendute né date in pegno, cedute in usufrutto o gravate di servitù". AGAMBEN, Giorgio. "Elogio alla profanazione". In:_. Profanazioni. Roma: Nottetempo, 2005, p. 83.

${ }_{24}$ "La secolarizzazione è una forma di rimozione, che lascia intatte le forze, che si limita a spostare da un luogo all'altro. Cosí la secolarizzazione politica di concetti teologici (la trascendenza di Dio come paradigma del potere sovrano) non fa che dislocare la monarchia celeste in monarchia terrena, ma ne lascia intatto il potere". AGAMBEN, Giorgio. Op. cit., p. 88. ${ }^{25}$ Schmitt, Carl. Teologia política (tradução de Elisete Antoniuk). Belo Horizonte: Del Rey, pp. 13-14 
exceção não é, portanto, o caos que precede a ordem, mas a situação que resulta da sua suspensão. Neste sentido, a exceção é verdadeiramente, segundo o étimo, capturada fora (ex-capere) e não simplesmente excluída ${ }^{26}$.

O mesmo filósofo, pensando também com Jean-Luc Nancy, define essa lógica de inclusão exclusiva como sendo uma relação de abandono - tudo aquilo "que foi posto em bando é remetido à própria separação e, juntamente, entregue à mercê de quem o abandona, ao mesmo tempo excluso e incluso, dispensado e, simultaneamente, capturado" ${ }^{27}$. Não há mais como simplesmente falar de um "está dentro" ou "está fora". O ser abandonado não está nem dentro nem fora e a reta execução da norma e a sua transgressão também já não podem mais ser diferenciadas.

Pode-se dizer, então, que a troca da exaltação de um "próprio" para a de um "impróprio" - em todo caso, ainda um pensamento da unidade - não é capaz de garantir a felicidade e a redenção daquilo que já foi - o passado mesmo. A felicidade não está nem na sacralidade e nem na secularização daquela separação fundadora do mundo, mas na esfera do mundo profano ${ }^{28}$. Inclusive daí parte o pensamento da profanação tal qual estudado por Agamben. Diferentemente da ordem sacra ou secular, ela é capaz de restituir aquilo que foi separado ao uso dos homens, no sentido de que uma ação profanadora abre "la possibilità di una forma speciale di negligenza, che ignora la separazione o, piuttosto, ne fa un uso particolare" ${ }^{29}$. Quando isso acontece, os dispositivos de poder que interditam o uso são desativados e a separação se torna inoperante. Se a de-cisão que identifica se configura pela constante rearticulação dos mecanismos de separação, Benjamin, na VIII Tese da filosofia da história, contrapunha um "efetivo estado de exceção" que passaria inclusive por uma noção de felicidade aberta à esfera do mundo profano. Nesse sentido, a felicidade e a redenção do passado não necessariamente se pautam pela reintegração hereditária do que já foi - o barroco mineiro dos séculos XVII e XVIII. No efetivo estado de exceção, não se trata mais de

\footnotetext{
${ }^{26}$ AGAMBEN, Giorgio. Homo sacer - o poder soberano e a vida nua (tradução de Henrique Burigo). Belo Horizonte: Editora da UFMG, 2002, p. 25

${ }^{27}$ AGAMBEN, Giorgio. Op. cit., p. 116.

${ }^{28}$ Este era não menos um dos motes de que se valia Walter Benjamin em seu fragmento teológico-político.

${ }^{29}$ AGAMBEN, Giorgio. Op. cit., p. 85.
} 
resgatar uma herança histórica renegada ou de estabelecer uma nova tradição $^{30}$, uma outra forma daquilo que seja comum - enquanto elemento de formação unitária - aos homens. Trata-se, pelo contrário, de interromper a tradição, e, dessa forma, poder reconhecer a potência daquilo que nunca aconteceu, a potência daquilo que a escrita da história decidiu por obliterar. Diante disso, não estranha que Agamben tenha podido dizer que a única exigência que de fato se impõe ao mundo profano é que todo existente exija a própria possibilidade, que exija se transformar em possibilidade ${ }^{31}$. Qualquer tentativa de determinar o homem - seja por uma propriedade seja por uma impropriedade - acaba por renegar a possibilidade de o ser existir enquanto potência, de existir enquanto manifestação da própria impropriedade ${ }^{32}$. Portanto, não basta mais pensar a marginalidade de um Aleijadinho como experiência determinante daquilo que é comum aO brasileiro - isto já entra na ordem do dia por meio da questão de como saber abandonar.

\footnotetext{
${ }^{30}$ AGAMBEN, Giorgio. "Walter Benjamin e il demonico. Felicità e redenzione storica nel pensiero di Benjamin". In:__. La potenza del pensiero - saggi e conferenze. Vicenza: Neri Pozza, 2005, p. 226.

31 "Nel De veritatibus primis Leibniz definisce la relazione tra possibilità e realtà in questo modo: omne possibile exigit existere, 'ogni possibili esige di esistere, di diventare reale'. Malgrado la mia incondizionata ammirazione per Leibniz, credo che questa formulazione non sai corretta e che, per definire che cosa sai veramente un'esigenza, dobbiamo rovesciarla e scrivere invece: omne existens exigit possibilitatem suam, 'ogni esistente esige la propria possibilità, esige di diventare possibile'. L'esigenza è una relazione fra ciò che è - o è stato - e la sua possibilità e questa non precede, ma segue la realtà". AGAMBEN, Giorgio. II tempo che resta - un commento alla Lettera ai Romani. Torino: Bollati Borighieri, 2000, pp. 42-43.

${ }^{32}$ AGAMBEN, Giorgio. La comunità che viene. Torino: Bollati Boringhieri, 2007, p. 15.
} 


\section{REFERÊNCIAS}

AGAMBEN, Giorgio. II tempo che resta - un commento alla Lettera ai Romani. Torino: Bollati Borighieri, 2000.

. Homo sacer - o poder soberano e a vida nua (tradução

de Henrique Burigo). Belo Horizonte: Editora da UFMG, 2002.

. Profanazioni. Roma: Nottetempo, 2005.

- "Walter Benjamin e il demonico. Felicità e redenzione storica nel pensiero di Benjamin". In: La potenza del pensiero - saggi e conferenze. Vicenza: Neri Pozza, 2005, pp. 205-235.

. La comunità che viene. Torino: Bollati Boringhieri, 2007.

AMARAL, Aracy A. "A Hispanidade em São Paulo. Da Casa Rural à Capela de Santo Antônio". In: Barroco, n. 7, Belo Horizonte, 1975, pp. 21-70.

ANDRADE, Mário de. "O Aleijadinho". In: . Aspectos das artes plásticas no Brasil. 3 ed. Belo Horizonte: Itatiaia, 1984, pp. 11-42

ÁVILA, Affonso. “Apresentação”. In: Barroco, n. 1, Belo Horizonte, 1969, pp. 0607.

. "O elemento lúdico nas formas da expressão do barroco". In: Barroco, n. 2, Belo Horizonte, 1970, pp. 07-18.

. "Pequena Iniciação ao Barroco Mineiro". In: Barroco, n. 7, Belo Horizonte, 1975, pp. 07-17.

. "O salto atlântico do barroco". In: Circularidade da ilusão e outros textos. São Paulo: Perspectiva, 2004, pp. 11-38.

. "Brasil: do barroco ao neobarroco. Três reflexões". In:

Circularidade da ilusão e outros textos. São Paulo: Perspectiva, 2004, pp. 39 48.

BARCA, Pedro Calderón de la. "El gran teatro del mundo". In: Teatro del Siglo de Oro (a cura di Mario Socrati, Maria Garzanti, Carmelo Samonà). Milano: Garzanti, 1990.

BATAILLE, Georges. "Arquitetura" (tradução de Marcelo Jacques de Moraes e João Camillo Penna). In: Revista Inimigo Rumor, n. 19, $2^{\circ}$ semestre de 2006 e $1^{\circ}$ semestre de 2007 , pp. $79-80$.

CAMPOS, Haroldo de. A Arte no Horizonte do Provável. 4. ed. São Paulo: Perspectiva, 1977. 
- O Seqüestro do Barroco na Formação da Literatura Brasileira: o caso Gregório de Mattos. 2 ed. Salvador: FCJA, 1989.

CAMPOS, Haroldo de. "Da razão antropofágica: diálogo e diferença na cultura brasileira". In: Metalinguagem \& outras metas: ensaios de teoria e crítica literária. 4 ed. São Paulo: Perspectiva, 2004, p. 231-255.

CÂNDIDO, Antônio. A educação pela noite e outros ensaios. São Paulo: Ática, 1987.

GRAVATÁ, Hélio. "Patrimônio Histórico e Artístico de Minas Gerais. Conservação e Proteção Oficial”. In: Barroco, n. 7, Belo Horizonte, 1975, pp. 102-121.

HOLANDA, Sérgio Buarque de. Raízes do Brasil. São Paulo: Companhia das Letras, 2006.

NANCY, Jean-Luc. L'essere abbandonato (tradução de Elettra Stimilli). Macerata: Quodlibet, 1995.

SCHMITT, Carl. Teologia Política (tradução de Elisete Antoniuk) Belo Horizonte: Del Rey, 2006.

VIEIRA, Antônio. "Sermão da Sexagésima". In:__. Sermões - Tomo I (organização de Alcir Pécora). São Paulo: Hedra, 2000. 